\title{
Outcomes and predictors of treatment failure following two-stage total joint arthroplasty with articulating spacers for evolutive septic arthritis
}

\author{
Chi Xu' ${ }^{1}$, Feng-Chih Kuo ${ }^{2}$, Matthew Kheir ${ }^{3}$, Xin $\mathrm{Li}^{4}$, Wei Chai ${ }^{1+}$ and Ji-Ying Chen ${ }^{1 *+}$
}

\begin{abstract}
Background: The treatment strategy for evolutive septic arthritis $(S A)$ with coexistent degenerative joint disease is not well established. The purposes of this study were to 1) investigate treatment outcome and potential risk factors of treatment failure in patients with evolutive SA following two-stage procedure, including insertion of an antibioticloaded spacer at the first stage and subsequent implantation of a new prosthesis; and 2) determine the performance of serum erythrocyte sedimentation rate (ESR), C-reactive protein (CRP), and Interleukin-6 (IL-6) in predicting persisting infection at second-stage procedure.
\end{abstract}

Methods: We retrospectively reviewed 74 patients with evolutive SA of hips and knees who underwent a two-stage TJA between 2008 and 2015. The treatment success was defined according to the modified Delphi criteria and KaplanMeier survivorship curves were constructed to determine treatment success. A Cox regression model was performed to identify risk factors for treatment failure. Receiver operating characteristic (ROC) curves were generated to determine the prognostic value of ESR, CRP, and IL-6 in predicting persistent infection before second-stage prostheses implantation.

Results: Overall, the treatment success rate was $93 \%$ for hips and $100 \%$ for knees after the first-stage surgery. The treatment success rate was $89 \%$ for hips and $84 \%$ for knees after second-stage prosthesis implantation with a mean follow-up of 4.7 (range, 2.2 to 10.8) years. Older age (Hazard ratio [HR] [per 10-year increase], 1.20; 95\% confidential interval [Cl], 1.11 to 1.62), higher preoperative CRP level (HR [per 1-mg/dL increase], 1.15; 95\% Cl, 1.04 to 1.28) and resistant organism (HR, 13.96; 95\% Cl, 3.29 to 19.20) were associated with an increased risk of treatment failure. All serologic tests presented limited values in predicting persisting infection, with the area under ROC curve of ESR, CRP, IL-6 and combination of the three markers was $57.8,61.6,60.3$, and $62.1 \%$, respectively.

Conclusions: Two-stage TJA is an adequate management of infection control in patients with evolutive SA. The three potential risk factors (old age, high preoperative CRP, and resistant organism profile) may predict treatment failure following a two-stage procedure for evolutive SA. Additionally, serum ESR, CRP, and IL-6 had no benefit in predicting persisting infection before second-stage prostheses implantation. These findings may be useful when treating patients with evolutive SA.

Keywords: Septic arthritis, Total joint arthroplasty, Erythrocyte sedimentation rate, C-reactive protein, Interleukin-6

\footnotetext{
* Correspondence: jiying_chen301@163.com

tWei Chai and Ji-Ying Chen contributed equally to this work and are considered as co-corresponding authors.

${ }^{1}$ Department of Orthopaedic Surgery, General Hospital of People's Liberation

Army, No.28 Fuxing Road, Haidian District, Beijing 100853, China

Full list of author information is available at the end of the article
}

(c) The Author(s). 2019 Open Access This article is distributed under the terms of the Creative Commons Attribution 4.0 International License (http://creativecommons.org/licenses/by/4.0/), which permits unrestricted use, distribution, and reproduction in any medium, provided you give appropriate credit to the original author(s) and the source, provide a link to the Creative Commons license, and indicate if changes were made. The Creative Commons Public Domain Dedication waiver (http://creativecommons.org/publicdomain/zero/1.0/) applies to the data made available in this article, unless otherwise stated. 


\section{Background}

The evolutive septic arthritis (SA) of the hip and knee in adults is a rare but dramatically disastrous disease. Evolutive SA is known to potentially cause devastating cartilage and bone damage as well as poor joint function overall [1, 2]. Recently, the incidence of SA is increasing owing to the aging population and more invasive joint procedures performed [3]. The treatment strategy for SA with coexistent degenerative joint disease is not well established. The use of a two-stage procedure, including insertion of an antibiotic-loaded spacer at the first stage followed by systemic antibiotic use and subsequent implantation of a new prosthesis, has been suggested in recent literature $[4,5]$. Although the success rate is high, there is around $10-15 \%$ failure rate in these certain population undergoing two-stage procedure for evolutive SA [5-9].

Studies have attempted to evaluate factors influencing outcomes of the two-stage exchange arthroplasty for periprosthetic joint infection (PJI), including patients' medical conditions, microbiologic results and laboratory tests [10-13]. However, the risk factors for failure following two-stage protocol for evolutive SA remains unknown, as the majority of studies mainly aimed at reporting on the treatment outcome [5-9]. Meanwhile, these studies were with small sample sizes and without standardized criteria for PJI. Most importantly, there was no standard guidance, such as serologic tests, to determine the optimal timing of the second-stage implantation while adopting two-stage procedure for evolutive SA. Therefore, it's crucial to identify risk factors of PJI following two-stage procedure for evolutive SA and to evaluate which serologic markers can accurately rule out persistent infection at the time of second stage implantation.

The purpose of this study was to 1) determine the rate of treatment success with the two-stage procedure for evolutive SA and identify potential risk factors of treatment failure, and 2) evaluate the performance of serologic markers in predicting persisting infection at the time of the second-stage procedure.

\section{Methods}

\section{Patients}

After the Institutional Review Board approval, we retrospectively reviewed patients $(n=89)$ who were teated with two-stage procedures to primary total joint arthroplasty for evolutive septic hips and knees between 2008 and 2015 in our institute. Nine patients with a follow-up less than 2 years were excluded. Six patients were also excluded as they did not undergo second-stage implantation. Therefore, a total of 74 patients with 74 joints (55 hips and 19 knees) were included in the final analyses.

\section{Definitions of evolutive septic arthritis}

The diagnosis of evolutive SA in this study was defined on the basis of one or more of the following $[4,8]$ : clinical signs of infection (local erythema, tenderness, effusion, limited range of motion, or the presence of a draining sinus communication with a joint), radiographic finding with loss of articular space, destruction of femoral heads or articular cartilage, laboratory serologic tests (C-reactive protein $[\mathrm{CRP}]>10 \mathrm{mg} / \mathrm{dL}$, erythrocyte sedimentation rate [ESR] $>30 \mathrm{~mm} / \mathrm{hr}$ ), purulence during operations, or positive synovial or tissue cultures at the first stage of antibiotic spacer placement.

\section{Two-stage protocol and postoperative treatment for evolutive septic arthritis}

An institutional standard protocol of two-stage procedures was performed. During the first-stage surgery, a femoral head or knee joint resection was performed. All infected and necrotic tissue was debrided thoroughly. Three to five cultures (synovial fluid, deep tissue and bone) were obtained for culture. The joints were irrigated with 5-9 L of an antiseptic solution. An antibiotic-loaded articulating cement spacer, containing 4-6g vancomycin and $2-4 \mathrm{~g}$ meropenem per $40 \mathrm{~g}$ bone cement (Heraeus Medical GmbH, Wehrheim/Ts., Germany) was then inserted. The combination of vancomycin and meropenem in the bone cement was utilized in accordance with our institutional infection control department, which explained that more than $90 \%$ of the organisms isolated from patients with PJI and septic arthritis were sensitive to one or both antibiotics. After the first-stage procedure, at least 6 weeks of systematic antibiotics were prescribed. The selection of systematic antibiotics was based on culture sensitivity reports and institutional guidelines with infectious disease specialists' consultation. In patients with negative microorganisms, an empiric, broad-spectrum antibiotic therapy was applied. The timing of implantation to a total hip or total knee arthroplasty was based on the following criteria: no clinical signs of infection, a wellhealed surgical wound, and gradually decreasing ESR and CRP values. All patients had a period of at least 2-week antibiotic holiday before second-stage surgery. As there was no "gold standard" in predicting persistent infection at the time of second-stage surgery, the diagnosis of persistent infection was made intraoperatively by combined consideration of lab tests, clinical and intraoperative findings. If patients had evidence of persistent infection, a repeated spacer exchange was performed. The mean interval between 1st stage and 2nd stage was $4.9 \pm 3.8$ months. During the second-stage procedure, the antibiotic-loaded cement spacer was removed and the prostheses were implanted followed by re-debridement and irrigation. Three to five samples of tissues for frozen sections were obtained during surgery from tissues in which infection 
was suspected. An antibiotic-loaded cement (Heraeus Medical GmbH, Wehrheim/Ts., Germany), containing $1 \mathrm{~g}$ vancomycin per $40 \mathrm{~g}$ bone cement was used if cemented fixation was required. Parenteral antibiotics were given postoperatively until the intraoperative cultures were negative findings.

\section{Data collection}

The medical records were reviewed manually in detail to retrieve pertinent information, including demographic data (gender, age, body mass index [BMI], and type of joint [knees or hips]), American Society of Anesthesiologists (ASA) score, comorbidities (diabetes mellitus, rheumatoid arthritis, smoker, alcohol abuse, coronary artery disease, and pulmonary disease), the origin of SA (postoperative, hematogenous, intra-articular injection or unknown), surgical variables (previous surgical history, the numbers of prior surgical procedures and intraoperative purulence), serologic tests (serum ESR, CRP, and interleukin-6) before second-stage implantation, and the infected organisms (Table 2). Serum interleukin-6 (IL-6) was available in 49 patients because the IL-6 test was introduced in our institution since 2012. Resistant organisms were defined as methicillin-resistant Staphylococcus aureus, methicillin-resistant Staphylococcus epidermidis and vancomycin-resistant Enterococcus. Any clinical signs of infection, infection-related mortality, additional spacer exchanges for infection or subsequent surgical intervention after second-stage implantation were all recorded.

\section{Outcome measurement}

The treatment success rate following first-stage surgery to an articulating cement spacer was defined as eradication of infection without any additional spacer exchanges. The treatment success following two-stage procedure to a total joint arthroplasty was defined by a modified Delphi criteria [14, 15]: (1) infection eradication characterized by a healed wound without drainage, fistula, or pain, with no recurrence of infection; (2) no occurrence of septic joint infection-related mortality; or (3) no any additional spacer exchanges and subsequent surgical intervention for infection after spacers implantation.

\section{Statistical analysis}

All of the statistical analyses were performed with the statistical software packages R (http://www.R-project.org, The $\mathrm{R}$ Foundation). The clinical characteristics between groups were compared with the use of the independent t-test or Mann-Whitney test for continuous variables and the chi-square test or Fisher's exact test for categorical variables. A Cox regression model was used to identify risk factors for treatment failure. Hazard ratios (HRs) and 95\% confidence intervals (CIs) were reported.
Kaplan-Meier survivorship curves were generated at the 1-year and 2-year follow-up. The log-rank test was used to evaluate the differences in survivorship between hips and knees. Receiver operating characteristic (ROC) curves were generated using Bootstrap resampling (times $=500$ ) to determine the prognostic value of serologic tests with treatment success as an outcome measure. The area under the ROC curve (AUC) with 95\% CI was calculated. A $p$-value less than 0.05 was considered statistically significant.

\section{Results}

Table 1 showed patients characteristics and organism profiles. There were 47 males and 27 females with a mean age (standard deviation) of $49.4 \pm 16.5$ years in the present study. The mean BMI was $24.7 \pm 4.4 \mathrm{~kg} / \mathrm{m}^{2}$ $\left(24.6 \pm 4.4 \mathrm{~kg} / \mathrm{m}^{2}\right.$ for hips and $24.9 \pm 4.4 \mathrm{~kg} / \mathrm{m}^{2}$ for $\left.\mathrm{knees}\right)$ . The primary source of infection was postoperative open trauma $(46 / 74,62.2 \%)$. Eight patients had a history of intra-articular infection before the onset of infection, and 7 patients presented with a history of hematogenous infection. The etiology of infection in the other 13 patients were unknown. Coagulase negative Staphylococcus was the most common organism (15/74, 20.3\%). Resistant organisms were found in 4 patients $(5.4 \%)$ and polymicrobial organisms were identified in 6 patients $(8.1 \%)$. The negative culture rate was $32.4 \%$ (24/74).

Overall, the treatment success rate was 93\% for hips and $100 \%$ for knees after the first-stage surgery. The treatment success rate was $89 \%$ for hips and $84 \%$ for knees after prosthesis implantation with a mean followup of 4.7 (range, 2.2 to 10.8) years. There was no infection-associated mortality. The survivorship of hip with treatment success as an endpoint was 94.4\% (95\% CI, 88.5 to $100 \%)$ at the 1 -year follow-up and $90.7 \%$ (95\% CI, 83.3 to $98.8 \%$ ) at the 2-year follow-up. The survivorship of knee was $94.7 \%$ (95\% CI, 85.2 to $100 \%$ ) at the 1-year follow-up and $89.5 \%$ (95\% CI, 76.7 to $100 \%$ ) at the 2-year follow-up. There was no significant difference in survivorship rate between hip and knee surgeries $(p=0.46)$ (Fig. 1). Additionally, four patients suffered from a spacer fracture and were treated conservatively. Spacer dislocation was observed in one case who was treated with conversion total hip arthroplasty. Following prosthesis implantation, eight patients had prolonged draining of the wound. One patient suffered from a prosthesis dislocation at the fourth month postoperatively and was treated by closed reduction.

The Cox regression result showed that older age (HR [per 10-year increase], 1.20; 95\% CI, 1.11 to 1.62 ), higher preoperative CRP level (HR [per 1-mg/dL increase], 1.15; 95\% CI, 1.04 to 1.28 ) and resistant organism (HR, 13.96; 95\% CI, 3.29 to 19.20 ) were associated with an increased risk of treatment failure after two-stage procedure (Table 2). 
Table 1 Characteristic, the origin of infection and organism profile of patients who underwent two-stage total joint arthroplasty for evolutive septic arthritis

\begin{tabular}{|c|c|c|c|}
\hline & Total $(n=74)$ & Hip $(n=55)$ & Knee $(n=19)$ \\
\hline \multicolumn{4}{|l|}{ Patient characteristics } \\
\hline $\mathrm{BMI}\left(\mathrm{kg} / \mathrm{m}^{2}\right)$ & $24.7 \pm 4.4$ & $24.6 \pm 4.4$ & $24.9 \pm 4.4$ \\
\hline Age (year) & $49.4 \pm 16.5$ & $45.8 \pm 16.0$ & $59.8 \pm 13.6$ \\
\hline Male & $47(63.5 \%)$ & $41(74.5 \%)$ & $6(31.6 \%)$ \\
\hline ASA score $\geq 3$ & $17(23.0 \%)$ & $11(20.0 \%)$ & $6(31.6 \%)$ \\
\hline \multicolumn{4}{|l|}{ Origin of infection } \\
\hline Postoperative & $46(62.2 \%)$ & $38(69.1 \%)$ & $8(42.1 \%)$ \\
\hline Hematogenous & $7(9.46 \%)$ & $5(9.1 \%)$ & $2(10.5 \%)$ \\
\hline Intra-articular injection & $8(10.8 \%)$ & $3(5.5 \%)$ & $5(26.3 \%)$ \\
\hline Unknown & $13(17.6 \%)$ & $9(16.4 \%)$ & $4(21.1 \%)$ \\
\hline \multicolumn{4}{|l|}{ Preoperative microorganism } \\
\hline Staphylococcus aureus & $6(8.1 \%)$ & $2(3.6 \%)$ & $4(21.1 \%)$ \\
\hline Resistant organism & $4(5.4 \%)$ & $2(3.6 \%)$ & $2(10.5 \%)$ \\
\hline Coagulase negative Staphylococcus & $15(20.3 \%)$ & $15(27.3 \%)$ & $0(0.0 \%)$ \\
\hline Gram-negative organism & $7(9.5 \%)$ & $6(10.9 \%)$ & $1(5.3 \%)$ \\
\hline Other organism & $12(16.2 \%)$ & $8(14.5 \%)$ & $4(21.1 \%)$ \\
\hline Polymicrobial organism & $6(8.1 \%)$ & $5(9.1 \%)$ & $1(5.3 \%)$ \\
\hline Culture negative organism & $24(32.4 \%)$ & 17 (30.9\%) & $7(36.8 \%)$ \\
\hline
\end{tabular}

$B M I$ Body mass index, ASA American Society of Anesthesiologists

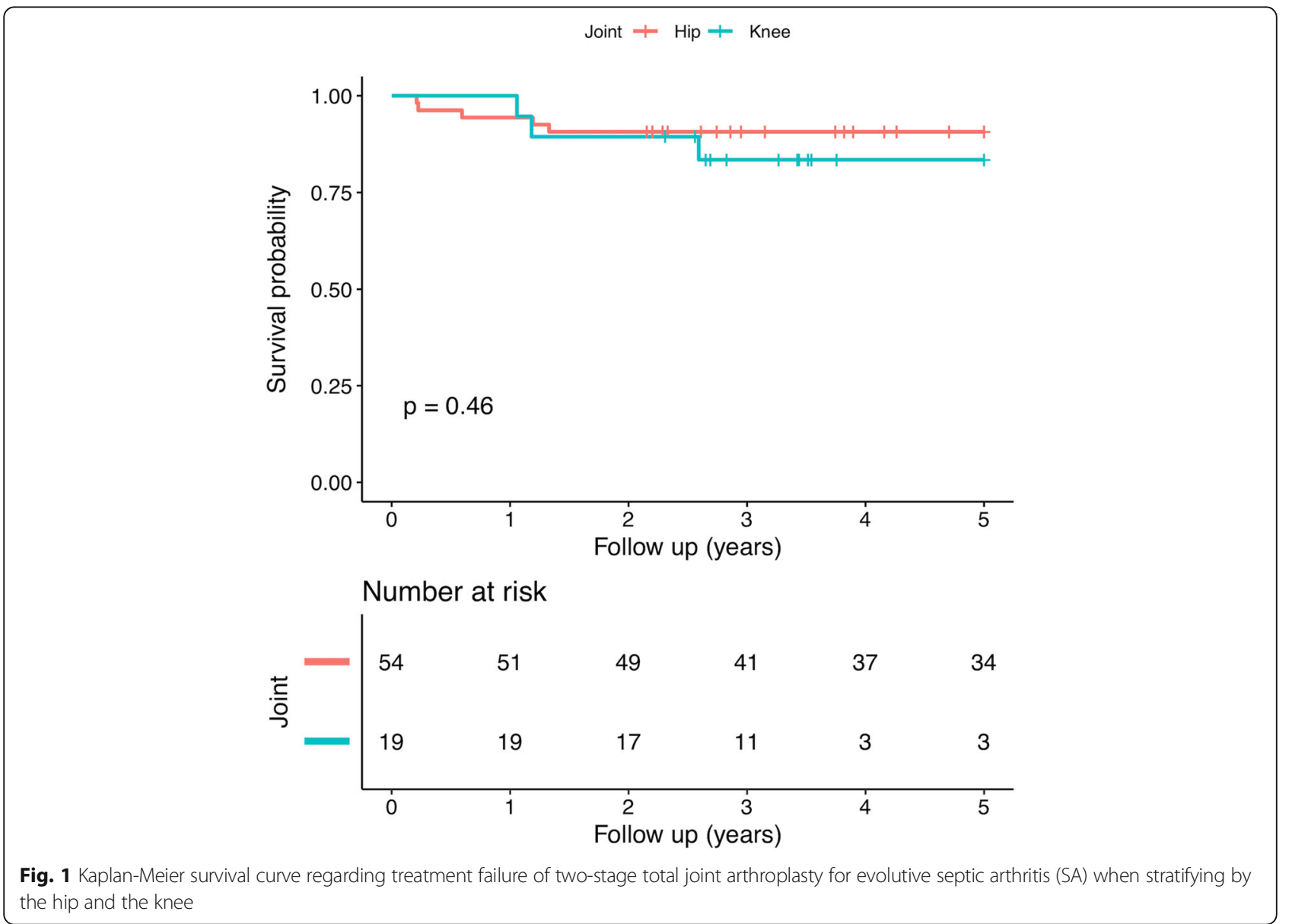


Table 2 Risk factors associated with treatment failure following two-stage protocol for active septic arthritis of hips and knees

\begin{tabular}{|c|c|c|c|c|}
\hline Variables & Success $(n=65)$ & Failure $(n=9)$ & HR $(95 \% \mathrm{Cl})$ & $p$-value \\
\hline \multicolumn{5}{|l|}{ Patient characteristics } \\
\hline Age (per 10-year increase) & $48.9 \pm 15.6$ & $53.0 \pm 23.3$ & $1.20(1.11,1.62)$ & 0.021 \\
\hline Male & $42(64.6 \%)$ & $5(55.6 \%)$ & $0.68(0.17,2.80)$ & 0.598 \\
\hline $\mathrm{BMI} \geq 30 \mathrm{~kg} / \mathrm{m}^{2}$ & $7(10.9 \%)$ & $1(12.5 \%)$ & $1.11(0.14,9.01)$ & 0.924 \\
\hline Knee & $16(24.6 \%)$ & $3(33.3 \%)$ & $1.43(0.36,5.71)$ & 0.615 \\
\hline \multicolumn{5}{|l|}{ Comorbidities } \\
\hline$A S A \geq 3$ & $14(21.5 \%)$ & $3(33.3 \%)$ & $1.82(0.75,7.31)$ & 0.186 \\
\hline Diabetes mellitus & $7(10.8 \%)$ & $2(22.2 \%)$ & $2.16(0.45,10.39)$ & 0.338 \\
\hline Rheumatoid arthritis & $4(6.2 \%)$ & $0(0.0 \%)$ & - & - \\
\hline Smoker & $9(13.8 \%)$ & $2(22.2 \%)$ & $1.77(0.37,8.52)$ & 0.477 \\
\hline Alcohol & $8(12.3 \%)$ & $2(22.2 \%)$ & $1.90(0.39,9.13)$ & 0.425 \\
\hline Coronary artery disease & $6(9.2 \%)$ & $1(11.1 \%)$ & $1.33(0.17,10.68)$ & 0.787 \\
\hline Pulmonary disease & $2(3.1 \%)$ & $1(11.1 \%)$ & $3.61(0.45,28.97)$ & 0.227 \\
\hline \multicolumn{5}{|l|}{ Surgical variables } \\
\hline Preoperative CRP (per-mg/dL) & $3.4 \pm 3.8$ & $8.1 \pm 10.4$ & $1.15(1.04,1.28)$ & 0.007 \\
\hline Preoperative ESR (per-mm/hr) & $46.0 \pm 28.2$ & $56.4 \pm 36.3$ & $1.01(0.98,1.05)$ & 0.397 \\
\hline IL-6 (per-pg/mL) & $7.4 \pm 9.0$ & $6.6 \pm 2.7$ & $1.01(0.97,1.06)$ & 0.540 \\
\hline Surgical history & $42(64.6 \%)$ & $4(44.4 \%)$ & $0.45(0.12,1.67)$ & 0.232 \\
\hline Prior surgical procedure(s) & $0.7 \pm 0.7$ & $0.9 \pm 1.4$ & $1.74(0.67,49.14)$ & 0.111 \\
\hline Intraoperative purulence & $35(53.8 \%)$ & $6(66.7 \%)$ & $1.72(0.43,6.87)$ & 0.444 \\
\hline \multicolumn{5}{|l|}{ Microbiology } \\
\hline Staphylococcus aureus & $5(7.7 \%)$ & $1(11.1 \%)$ & $1.31(0.16,10.52)$ & 0.797 \\
\hline Resistant organism & $1(1.5 \%)$ & $3(33.3 \%)$ & $13.96(3.29,19.20)$ & $<0.001$ \\
\hline Coagulase negative Staphylococcus & $13(20.0 \%)$ & $2(22.2 \%)$ & $1.31(0.23,5.43)$ & 0.881 \\
\hline Gram-negative organism & $6(9.2 \%)$ & $1(11.1 \%)$ & $1.17(0.15,9.40)$ & 0.879 \\
\hline Other organism & $11(16.9 \%)$ & $1(11.1 \%)$ & $0.67(0.08,5.37)$ & 0.707 \\
\hline Polymicrobial organism & $5(7.7 \%)$ & $1(11.1 \%)$ & $1.47(0.18,11.74)$ & 0.718 \\
\hline
\end{tabular}

BMI Body mass index, ASA American Society of Anesthesiologists, ESR Erythrocyte sedimentation rate, CRP C-reactive protein, IL-6 Interleukin-6

Male (HR, $0.68 ; 95 \% \mathrm{CI}, 0.17$ to 2.80 ), obesity (BMI $\geq 30 \mathrm{~kg} / \mathrm{m}^{2}, \mathrm{HR}, 1.11 ; 95 \% \mathrm{CI}, 0.14$ to 9.01$)$, knee (HR, $1.43 ; 95 \% \mathrm{CI}, 0.36$ to 5.71 ), ASA score $\geq 3$ (HR, 1.82; 95\% CI, 0.75, 7.31), diabetes (HR, 2.16; 95\% CI, 0.45 to 10.39 ), smoker ( $\mathrm{HR}, 1.77 ; 95 \% \mathrm{CI}, 0.37$ to 8.52 ), alcohol abuse (HR, 1.90; 95\% CI, 0.39 to 9.13$)$, coronary artery disease (HR, 1.33 ; $95 \% \mathrm{CI}, 0.17$ to 10.68 ), pulmonary disease (HR, 3.61; 95\% CI, 0.45 to 28.97 ), higher preoperative ESR level (HR [per 1-mm/hr. increase], 1.01; 95\% CI, 0.98 to 1.05 ), higher IL-6 level (HR [per 1-pg/mL increase], $1.01 ; 95 \% \mathrm{CI}, 0.97$ to 1.06 ), surgical history (HR, 0.45 ; $95 \%$ CI, 0.12 to 1.67 ), number of surgical procedures (HR [Per-1 increase], 1.74; 95\% CI, 0.67 to 49.14), intraoperative purulence (HR, 1.72; 95\% CI, 0.43 to 6.87), Staphylococcus aureus (HR, 1.31; 95\% CI, 0.16 to 10.52), coagulase negative Staphylococcus (HR, 1.31; 95\% CI, 0.23 to 5.43), gram-negative organism (HR, 1.17; 95\% CI, 0.15 to 9.40$)$ and polymicrobial organism (HR, 1.47; 95\% CI,
0.18 to 11.74 ) were not significantly associated with treatment failure.

The serum CRP, ESR or IL-6 values before prostheses implantation were not significantly different between treatment success and failure group (Table 3). The ROC curves for the diagnosis of persistent infection were depicted in Fig. 2. All serologic tests showed poor prognostic value in predicting persisting infection, with the AUC of $61.6 \%$ (95\% CI, 42.2 to $80.2 \%$ ) for CRP, $57.8 \%$ (95\% CI, 37.2 to $78.8 \%$ ) for ESR, $60.3 \%$ (95\% CI, 43.5 to

Table 3 Serologic tests before prostheses implantation

\begin{tabular}{llll}
\hline Variables & Success & Failure & $p$-value \\
\hline CRP $(\mathrm{mg} / \mathrm{dL})$ & $0.8 \pm 0.8$ & $1.1 \pm 1.0$ & 0.134 \\
ESR $(\mathrm{mm} / \mathrm{hr})$ & $15.7 \pm 18.0$ & $19.7 \pm 19.4$ & 0.518 \\
IL-6 $(\mathrm{pg} / \mathrm{mL})$ & $8.1 \pm 8.0$ & $9.9 \pm 9.8$ & 0.404 \\
\hline
\end{tabular}

ESR Erythrocyte sedimentation rate, CRP C-reactive protein, IL-6 Interleukin-6 

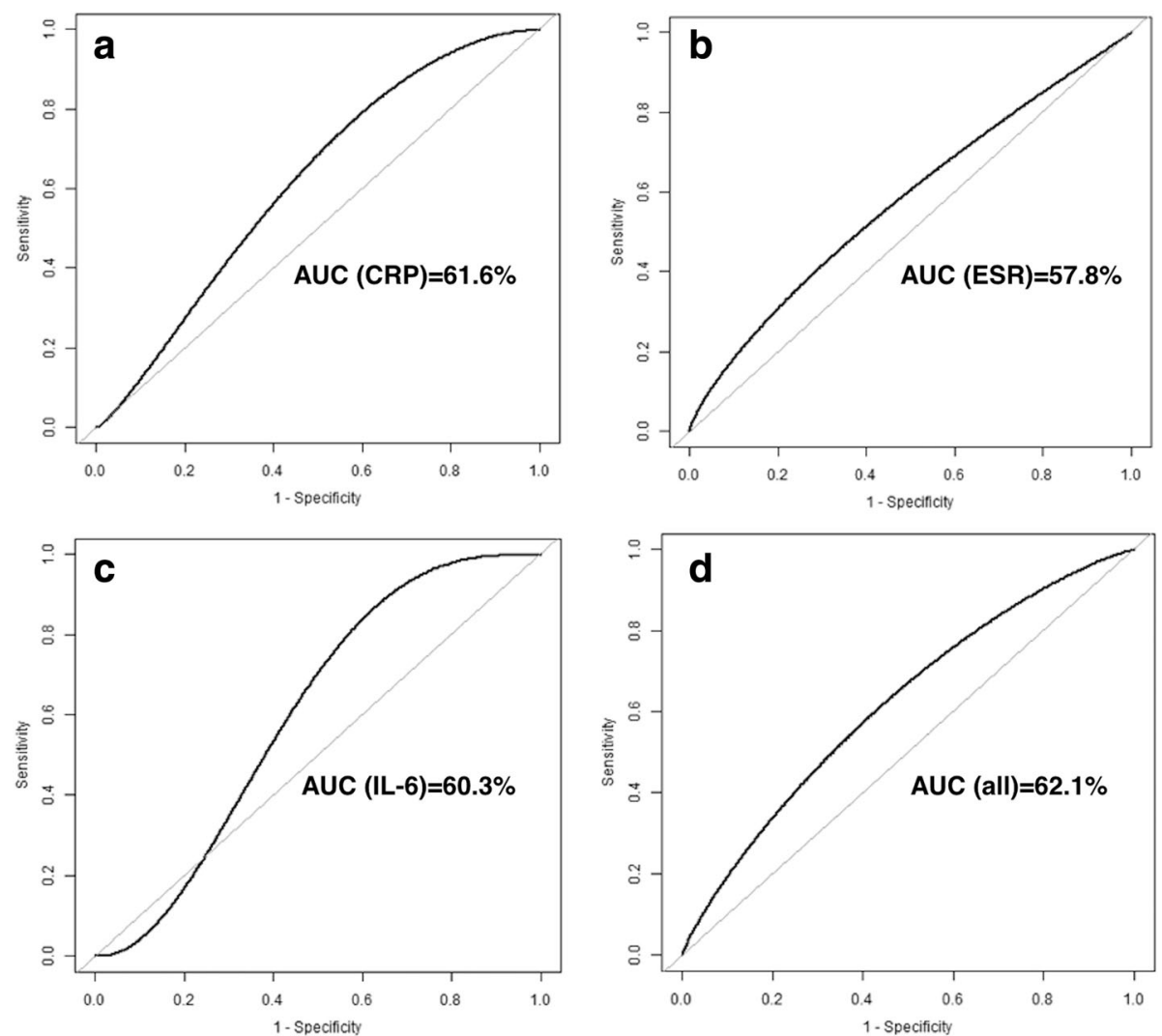

Fig. 2 Receiver operating characteristic (ROC) curve for serum laboratory tests in diagnosing persistent infection before implantation of protheses in patients with evolutive SA: a C-reactive protein (CRP); $\mathbf{b}$ erythrocyte sedimentation rate (ESR); $\mathbf{c}$ interleukin-6 (IL-6); and $\mathbf{d}$ combination of the three serologic tests

$73.3 \%)$ for IL-6, and $62.1 \%$ (42.4 to $81.0 \%)$ for the combination of the three tests.

\section{Discussion}

The present study showed a satisfactory success rate of treatment with a two-stage procedure to a total joint arthroplasty (TJA) for evolutive SA of hips and knees. Older age, higher preoperative CRP level, and resistant organisms were associated with an increased risk of treatment failure. Additionally, the serological tests (ESR, CRP and IL-6) showed poor sensitivity and specificity in predicting persisting infection before secondstage prostheses implantation.

The management of evolutive SA with a coexisting degeneration joint disease remains difficult. Although prior data have reported benefits of one-stage TJA for patients with quiescent SA, there has been an increased risk of PJI following TJA [16, 17]. Furthermore, patients with active SA were contraindicated to one-stage TJA. Recently, the two-stage procedure to a TJA may be considered as a worthy alternative in the management of SA [2, 4, 5]. Papanna et al. [2] reported on 18 cases with SA who underwent one-stage or two-stage TJA based on whether the infection was active or quiescent. There was no reinfection or implant failure in this cohort at a mean follow-up of 70 months. Anagnostakos et al. [4] treated 22 patients with SA who underwent two-stage TJA. Eventually, 16 patients underwent prosthesis implantation at an average of 88 days after spacer implantation and the primary infection control rate was $87 \%$. However, surgeons should take related complications into consideration, especially the higher mortality rate following two-stage procedures compared with other treatment methods, such as one-stage TJA. Zachary et al. conducted a meta-analysis and the pooled data suggested one-year mortality rate was $4.33 \%$ after total knee PJI with an increase of $3.13 \%$ per year mortality thereafter [18]. Another meta-analysis by Natsuhara et al. indicated one-year mortality rate was $4.22 \%$ after total hip PJI and 5-year mortality rate was $21.12 \%$. Therefore, this highlights the importance in evaluating patients' health conditions when determining to perform a two-stage procedure.

In our series of patients, the overall success rate was 94.6\% after the first-stage surgery and $87.8 \%$ after prosthesis implantation, with a comparable incidence observed for patients with SA of the hip and knee. Although our 
results are similar with previous studies (Table 4), the success rates of the present study are near the lower end of rates previously reported. The reason may be that most of the studies with success rate of more than $90 \%$ included small sample sizes [23, 24]. Another explanation is that our cohort had more gram-negative infections and polymicrobial infections, which have been suggested to be associated with worse outcomes following two-stage exchange arthroplasty for PJI [25-27].

A total of 23 risk factors for potential treatment failure following two-stage TJA were investigated. Among them, only older age, higher preoperative CRP level, and resistant organisms were associated with an increased risk of treatment failure, which were in line with previous studies that evaluated risk factors for treatment failure following two-stage exchange arthroplasty for chronic PJI [10, 28, 29]. Several studies have suggested resistant organisms are associated with treatment failure after two-stage exchange arthroplasty of PJI [30, 31]. Older age was associated with gram-negative PJI and polymicrobial PJI that had higher failure rates [32, 33]. Recently, Dwyer et al. reported higher laboratory tests for diagnosis of PJI could help

Table 4 Overview of current researches that reported more than five cases who underwent a two-stage procedure to a total joint arthroplasty for septic arthritis

\begin{tabular}{|c|c|c|c|c|c|c|c|c|c|c|}
\hline Study & Num. & $\begin{array}{l}\text { Spacer } \\
\text { type }\end{array}$ & $\begin{array}{l}\text { Antibiotic } \\
\text { in spacer }\end{array}$ & $\begin{array}{l}\text { Duration of } \\
\text { antibiotic } \\
\text { before } \\
\text { reimplantation } \\
\text { (weeks) }\end{array}$ & $\begin{array}{l}\text { Period } \\
\text { between } \\
\text { stages } \\
\text { (weeks) }\end{array}$ & $\begin{array}{l}\text { Surgery } \\
\text { between } \\
\text { stages }\end{array}$ & $\begin{array}{l}\text { Success } \\
\text { rate after } \\
\text { first-stage } \\
\text { surgery }\end{array}$ & $\begin{array}{l}\text { Duration of } \\
\text { antibiotic after } \\
\text { reimplantation } \\
\text { (days) }\end{array}$ & $\begin{array}{l}\text { Mean } \\
\text { follow- } \\
\text { up } \\
\text { (months) }\end{array}$ & $\begin{array}{l}\text { Success } \\
\text { rate after } \\
\text { prosthesis } \\
\text { implantation }\end{array}$ \\
\hline \multicolumn{11}{|l|}{ Hip } \\
\hline $\begin{array}{l}\text { Anagnostakos } \\
2016[4]\end{array}$ & 16 & $\mathrm{HM}$ & $\begin{array}{l}\text { GEN }(1.3 \%)+\text { VAN } \\
(5 \%)\end{array}$ & 6 & 13 & $\begin{array}{l}2 \mathrm{SE}+1 \\
\text { Girdlestone }\end{array}$ & $81 \%$ & 0 & 45 & $87 \%$ \\
\hline $\begin{array}{l}\text { Bauer } \\
2010[9]\end{array}$ & 13 & NP & Without antibiotics & 6 & 13 & NP & NP & NP & 60 & $85 \%$ \\
\hline $\begin{array}{l}\text { Chen } \\
2008 \text { [19] }\end{array}$ & 28 & Beads & OXA + GEN & $>4$ & 15 & $\begin{array}{l}2 \\
\text { Girdlestone }\end{array}$ & $93 \%$ & 42 & 77 & $86 \%$ \\
\hline $\begin{array}{l}\text { Diwanji } \\
2008[20]\end{array}$ & 9 & $\mathrm{HM}$ & VAN (4.9\%) & NP & 23 & $1 \mathrm{SE}$ & $89 \%$ & 3 to 5 & 42 & $89 \%$ \\
\hline $\begin{array}{l}\text { Fleck } \\
2011[5]\end{array}$ & 10 & HM & $\begin{array}{l}\text { GEN or TOB ( } 9 \text { to } \\
12 \%)+ \text { VAN (5 to } \\
7.5 \%)+ \text { Ancef }(5 \%)\end{array}$ & 6 & 44 & $1 \mathrm{SE}$ & $90 \%$ & NP & 28 & $100 \%$ \\
\hline $\begin{array}{l}\text { Huang } \\
2010[21]\end{array}$ & 14 & $\mathrm{HM}$ & $\begin{array}{l}\text { VAN }(10 \%)+\text { AZT } \\
(10 \%)\end{array}$ & 1 & 13 & $1 \mathrm{SE}$ & $93 \%$ & 3 & 43 & $100 \%$ \\
\hline $\begin{array}{l}\text { Kelm } 2009 \\
\text { [22] }\end{array}$ & 8 & $\mathrm{HM}$ & VAN (5\%) & 6 & 12 & 0 & $100 \%$ & NP & 12 & $87.5 \%$ \\
\hline $\begin{array}{l}\text { Papanna } \\
2018[2]\end{array}$ & 11 & Beads & VAN (5\%) & NP & 28 & NP & NP & NP & 70 & $100 \%$ \\
\hline $\begin{array}{l}\text { Romano } \\
2011[6]\end{array}$ & 19 & $\mathrm{COM}$ & $\begin{array}{l}\text { GEN }(1.9 \%)+\text { VAN } \\
(5 \%)\end{array}$ & 4 & 22 & 0 & $100 \%$ & 28 & 57 & $95 \%$ \\
\hline $\begin{array}{l}\text { Shen } \\
2013 \text { [23] }\end{array}$ & 5 & $\mathrm{HM}$ & $\begin{array}{l}\text { GEN }(1.3 \%)+\text { VAN } \\
(8.8 \%)\end{array}$ & $>6$ & 19 & 0 & $100 \%$ & NP & 40 & $100 \%$ \\
\hline This study & 55 & $\mathrm{HM}$ & $\begin{array}{l}\text { VAN }(10-15 \%)+\text { MER } \\
(5-10 \%)\end{array}$ & $>4$ & 23 & $4 \mathrm{SE}$ & $93 \%$ & 5 & 62 & $89 \%$ \\
\hline \multicolumn{11}{|l|}{ Knee } \\
\hline $\begin{array}{l}\text { Bauer } \\
2010[9]\end{array}$ & 17 & NP & Without antibiotics & 6 & 13.3 & NP & NP & $\mathrm{NP}$ & 60 & $88 \%$ \\
\hline $\begin{array}{l}\text { Kirpalani } \\
2005[24]\end{array}$ & 5 & Beads & NP & NP & NP & 0 & $100 \%$ & 0 & 38.4 & $100 \%$ \\
\hline $\begin{array}{l}\text { Nazarian } \\
2003[7]\end{array}$ & 14 & $\mathrm{HM}$ & $\begin{array}{l}\text { TOB (5-10\%) + VAN } \\
(2.5 \%)\end{array}$ & $>6$ & 12.4 & 0 & $100 \%$ & $>185$ & 54 & $100 \%$ \\
\hline $\begin{array}{l}\text { Shaikh } \\
2000[8]\end{array}$ & 13 & $\mathrm{HM}$ & VAN $(10 \%)+\operatorname{STR}(5 \%)$ & $>2$ & 22.4 & $1 \mathrm{SE}$ & $92 \%$ & $>42$ & 48 & $100 \%$ \\
\hline This study & 19 & $\mathrm{HM}$ & $\begin{array}{l}\text { VAN }(10-15 \%)+\text { MER } \\
(5-10 \%)\end{array}$ & $>4$ & 20.2 & 0 & $100 \%$ & 5 & 40.3 & $84 \%$ \\
\hline
\end{tabular}


predict outcomes of two-stage exchange arthroplasty [11]. Additionally, other factors have been identified to associate with treatment failure among different studies. Ma et al. [30] examined 106 patients (108 knees) of PJI treated with two-stage exchange arthroplasty using 31 risk factors, and they found obesity, prolonged operative time, a history of gout and Enterococcal infection were associated with an increased risk of treatment failure. Sabry et al. [29] attempted to develop a preoperative prognostic model by evaluating patients' individual risks for treatment failure following 314 knee PJIs that underwent twostage exchange arthroplasty. Although the model showed satisfying results (AUC, 0.773), they were limited due to a small number of variables used in assessing treatment failure and a short follow-up. Kheir et al. [28] created a predictive calculator for surgical treatment of PJI using 1438 PJIs treated at two institutions with a total of 63 risk factors at a minimum follow-up was one year. Overall, they found ten significant risk factors for PJI treatment failure, including irrigation and debridement, history of myocardial infarction, revision surgery, presence of sinus tract, resistant organisms, ever smoker, numbers of prior surgery, synovial white blood cell count, obesity, and ESR value. However, the aforementioned models were hampered by the lack of adequately external validation.

Our results found the accuracy of serological tests, including ESR, CRP and IL-6, was poor in predicting persisting infection before second-stage prostheses implantation, which was similar with previous studies on the two-stage exchange arthroplasty of PJI. Ghanem et al. [34] reported 109 PJIs who underwent two-stage exchange arthroplasty at a single institution and suggested that ESR and CRP both had poor diagnostic performance (AUC of 0.5 and 0.54, respectively) before second-stage reimplantation. Likewise, Shukla et al. [35] reviewed 87 hip PJIs and found the poor accuracy of ESR and CRP in predicting persisting infection. A study by Kusuma et al. [36] reviewed 76 PJI cases underwent two-stage exchange arthroplasty. Although patients with infection control presented decreased ESR and CRP level before reimplantation, they failed to identify any patterns predictive of persistent infection due to their poor sensitivity and specificity. Most recently, Hoell et al. [37] reported 55 PJIs and suggested serum IL-6 was a valuable test in predicting persistent infection before reimplantation. Their results showed that the AUC of IL- 6 was 0.896 and an optimal cutoff value of $\geq 13 \mathrm{pg} / \mathrm{ml}$ to diagnose persistent infection. However, the present study with a comparable patient sample failed to identify benefits of IL-6 in predicting persistent infection. Further studies with greater sample sizes are needed to validate these results. Additionally, some tests present promising performance in diagnosing persist infection. Several studies showed sonication of antibiotic spacers could disrupted biofilm and led to higher rates of positive intraoperative cultures [38, 39]. Kheir et al. reported that positive leukocyte esterase (LE) strip test might be used in diagnosing persistent infection and resulted in a higher rate of subsequent failure [26]. Recently, Shahi et al. reported D-dimer might be useful in diagnosing infection before reimplantation [16]. However, a meta-analysis by Lee et al. reviewed 12 studies and suggested that no single marker was superior to all the others [38]. The diagnosis of persistent infection should rely on the combination of all available tests [39].

Several limitations should be considered. Most notably, the design was retrospective and certain biases of retrospective study are inherent. For instance, types of surgery before infection and duration of infection before surgery were not available. Second, although to our best knowledge, the present study had the largest sample size in the literature, the number of patients remains small. Therefore, we didn't separate hip and knee SA in identifying risk factors of treatment failure, which may result in under power. Third, many patients included in the present study were referred to our institution after initial management in another facility, which may result in selection bias. Fourth, although an institutional standard protocol of two-stage procedures was conducted, the treatment regime (such as antibiotic administration, the duration between first stage and second stage, antibiotic holiday before second stage) was individual. Additionally, surgeon preference of treatment regime may be a factor, which may introduce bias. Fifth, as the majority of patients with SA were treated with a two-stage procedure, we cannot compare with different treatments, such as irrigation and debridement and one-stage TJA. Further studies are needed to evaluate and compare the outcomes of different procedures. Sixth, the minimum 2-year follow-up limited to represent the long-term outcomes. Lastly, the best "cut-offs" of markers for assessment of persistent infection before second-stage surgery was not presented due to limited predictive values of these markers.

\section{Conclusions}

Two-stage TJA is an adequate management of infection control in patients with evolutive SA. Older age, preoperative high CRP level and resistant organisms are potential risk factors of treatment failure. Additionally, serum ESR, CRP, and IL-6 had no benefit in predicting persisting infection before second-stage prostheses implantation. With the goal of optimizing risk factors and improving outcomes, further studies with larger cohorts are needed to validate these risk factors and search timely biomarkers with higher accuracies in predicting persistent infection at the time of conversion TJA.

\section{Abbreviations}

ASA: American Society of Anesthesiologists; AUC: Area under the ROC curve; Cl: Confidence intervals; CRP: C-reactive protein; ESR: Serum erythrocyte 
sedimentation rate; HR: Hazard ratios; IL-6: Interleukin-6; PJI: Periprosthetic joint infection; ROC: Score Receiver operating characteristic; SA: Septic arthritis; TJA: Total joint arthroplasty

\section{Acknowledgments}

The authors would like to thank all staff from the participating departments and clinics.

\section{Authors' contributions}

Conceptualization, C.X., F.C.K. and J.Y.C.; methodology, C.X., W.C. and J.Y.C.; validation, C.X., F.C.K., M.K., W.C. and J.Y.C.; formal analysis, C.X.; investigation, C.X., W.C. and X.L.; data curation, C.X. and X.L.; writing—original draft preparation, C.X., F.C.K. and M.K.; writing - review and editing, F.C.K., W.C. and J.Y.C.; visualization, F.C.K. and J.Y.C.; supervision, W.C. and J.Y.C. All authors read and approved the final manuscript.

\section{Funding}

Not applicable.

\section{Availability of data and materials}

Data are available on request from the authors.

\section{Ethics approval and consent to participate}

This study was approved by the Ethics Committee of the General Hospital of People's Liberation Army and in accordance with the 1964 Declaration of Helsinki. Written informed consent was obtained from all participants.

\section{Consent for publication}

Not applicable.

\section{Competing interests}

The authors declare that they have no competing interests.

\section{Author details}

'Department of Orthopaedic Surgery, General Hospital of People's Liberation Army, No.28 Fuxing Road, Haidian District, Beijing 100853, China. 2Department of Orthopaedic Surgery, Kaohsiung Chang Gung Memoria Hospital, Kaohsiung, Taiwan. ${ }^{3}$ University of Minnesota Medical School, Minneapolis, MN, USA. ${ }^{4}$ Department of Orthopaedic Surgery, Xingtai People's Hospital, Xingtai, Hebei Provence, China.

Received: 19 November 2018 Accepted: 23 May 2019

Published online: 03 June 2019

\section{References}

1. Matthews PC, Dean BJF, Medagoda K, Gundle R, Atkins BL, Berendt AR, et al. Native hip joint septic arthritis in 20 adults: delayed presentation beyond three weeks predicts need for excision arthroplasty. J Inf Secur. 2008:57:185-90

2. Papanna MC, Chebbout R, Buckley S, Stockley I, Hamer A. Infection and failure rates following total hip arthroplasty for septic arthritis: a casecontrolled study. HIP Int. 2018;28:63-7.

3. Nair R, Schweizer ML, Singh N. Septic arthritis and prosthetic joint infections in older adults. Infect Dis Clin N Am. 2017:31:715-29.

4. Anagnostakos K, Duchow L, Koch K. Two-stage protocol and spacer implantation in the treatment of destructive septic arthritis of the hip joint. Arch Orthop Trauma Surg. 2016;136:899-906.

5. Fleck EE, Spangehl MJ, Rapuri VR, Beauchamp CP. An articulating antibiotic spacer controls infection and improves pain and function in a degenerative septic hip. Clin Orthop Relat Res. 2011;469:3055-64.

6. Romanò $\mathrm{CL}$, Romanò $\mathrm{D}$, Meani E, Logoluso N, Drago L. Two-stage revision surgery with preformed spacers and cementless implants for septic hip arthritis: a prospective, non-randomized cohort study. BMC Infect Dis. 2011; 11. https://doi.org/10.1186/1471-2334-11-129.

7. Nazarian DG, de Jesus D, McGuigan F, Booth RE. A two-stage approach to primary knee arthroplasty in the infected arthritic knee. J Arthroplast. 2003; 18(7 Suppl 1):16-21.

8. Shaikh AA, Ha C-W, Park Y-G, Park Y-B. Two-stage approach to primary TKA in infected arthritic knees using intraoperatively molded articulating cement spacers. Clin Orthop Relat Res. 2014;472:2201-7.
9. Bauer T, Lacoste S, Lhotellier L, Mamoudy P, Lortat-Jacob A, Hardy P. Arthroplasty following a septic arthritis history: a 53 cases series. Orthop Traumatol Surg Res. 2010;96:840-3.

10. Ma C-Y, Lu Y-D, Bell KL, Wang J-W, Ko J-Y, Wang C-J, et al. Predictors of treatment failure after 2-stage reimplantation for infected total knee arthroplasty: a 2- to 10-year follow-up. J Arthroplast. 2018;33:2234-9.

11. Dwyer MK, Damsgaard C, Wadibia J, Wong G, Lazar D, Smith E, et al. Laboratory tests for diagnosis of chronic periprosthetic joint infection can help predict outcomes of two-stage exchange. J Bone Joint Surg Am. 2018;100:1009-15.

12. Xu C, Wang Q, Kuo F-C, Goswami K, Tan TL, Parvizi J. The presence of sinus tract adversely affects the outcome of treatment of periprosthetic joint infections. J Arthroplast. 2019. https://doi.org/10.1016/j.arth.2019.02.040.

13. $\mathrm{Xu} C$, Tan $T L$, Chen J-Y. Positive culture during reimplantation increases the risk of reinfection in two-stage exchange arthroplasty despite administrating prolonged antibiotics: a retrospective cohort study and meta-analysis. J Arthroplast. 2019. https://doi.org/10.1016/j.arth.2019.01.039

14. Diaz-Ledezma C, Higuera CA, Parvizi J. Success after treatment of periprosthetic joint infection: a Delphi-based international multidisciplinary consensus. Clin Orthop Relat Res. 2013;471:2374-82.

15. Tan TL, Goswami K, Fillingham YA, Shohat N, Rondon AJ, Parvizi J. Defining treatment success after 2-stage exchange arthroplasty for periprosthetic joint infection. J Arthroplast. 2018;33:3541-6.

16. Seo J-G, Moon Y-W, Park S-H, Han K-Y, Kim S-M. Primary total knee arthroplasty in infection sequelae about the native knee. J Arthroplast. 2014:29:2271-5.

17. Jupiter JB, Karchmer AW, Lowell JD, Harris WH. Total hip arthroplasty in the treatment of adult hips with current or quiescent sepsis. J Bone Joint Surg Am. 1981;63:194-200.

18. Lum ZC, Natsuhara KM, Shelton TJ, Giordani M, Pereira GC, Meehan JP. Mortality during total knee periprosthetic joint infection. J Arthroplast. 2018;33:3783-8.

19. Chen C-E, Wang J-W, Juhn R-J. Total hip arthroplasty for primary septic arthritis of the hip in adults. Int Orthop. 2008:32:573-80.

20. Diwanji SR, Kong IK, Park YH, Cho SG, Song EK, Yoon TR. Two-stage reconstruction of infected hip joints. J Arthroplast. 2008;23:656-61.

21. Huang T-W, Huang K-C, Lee P-C, Tai C-L, Hsieh P-H. Encouraging outcomes of staged, uncemented arthroplasty with short-term antibiotic therapy for treatment of recalcitrant septic arthritis of the native hip. J Trauma. 2010;68:965-9.

22. Kelm J, Bohrer P, Schmitt E, Anagnostakos K. Treatment of proximal femur infections with antibiotic-loaded cement spacers. Int J Med Sci. 2009:6:258-64.

23. Shen $\mathrm{H}$, Wang $\mathrm{Q}-\mathrm{J}$, Zhang $\mathrm{X}-\mathrm{L}$, Jiang $\mathrm{Y}$. Novel articulating medullarysparing spacer for the treatment of infectious hip arthritis. Orthopedics. 2013;36:e404-8.

24. Kirpalani PA, In Y, Choi NY, Koh HS, Kim JM, Han CW. Two-stage total knee arthroplasty for non-salvageable septic arthritis in diabetes mellitus patients. Acta Orthop Belg. 2005:71:315-20.

25. Zmistowski B, Fedorka CJ, Sheehan E, Deirmengian G, Austin MS, Parvizi J. Prosthetic joint infection caused by gram-negative organisms. J Arthroplast. 2011;26(6 Suppl):104-8.

26. Jhan S-W, Lu Y-D, Lee MS, Lee C-H, Wang J-W, Kuo F-C. The risk factors of failed reimplantation arthroplasty for periprosthetic hip infection. BMC Musculoskelet Disord. 2017:18:255.

27. Wimmer MD, Friedrich MJ, Randau TM, Ploeger MM, Schmolders J, Strauss $A A$, et al. Polymicrobial infections reduce the cure rate in prosthetic joint infections: outcome analysis with two-stage exchange and follow-up $\geq$ two years. Int Orthop. 2016:40:1367-73.

28. Kheir MM, Tan TL, George J, Higuera CA, Maltenfort MG, Parvizi J. Development and evaluation of a prognostic calculator for the surgical treatment of periprosthetic joint infection. J Arthroplast. 2018;33:2986-92 e1.

29. Sabry FY, Buller L, Ahmed S, Klika AK, Barsoum WK. Preoperative prediction of failure following two-stage revision for knee prosthetic joint infections. J Arthroplast. 2014;29:115-21.

30. Parvizi J, Azzam K, Ghanem E, Austin MS, Rothman RH. Periprosthetic infection due to resistant staphylococci: serious problems on the horizon. Clin Orthop Relat Res. 2009:467:1732-9.

31. Kurd MF, Ghanem E, Steinbrecher J, Parvizi J. Two-stage exchange knee arthroplasty: does resistance of the infecting organism influence the outcome? Clin Orthop Relat Res. 2010;468:2060-6. 
32. Hsieh P-H, Lee MS, Hsu K-Y, Chang Y-H, Shih H-N, Ueng SW. Gram-negative prosthetic joint infections: risk factors and outcome of treatment. Clin Infect Dis. 2009;49:1036-43.

33. Marculescu CE, Cantey JR. Polymicrobial prosthetic joint infections: risk factors and outcome. Clin Orthop Relat Res. 2008;466:1397-404.

34. Ghanem E, Azzam K, Seeley M, Joshi A, Parvizi J. Staged revision for knee arthroplasty infection: what is the role of serologic tests before Reimplantation? Clin Orthop Relat Res. 2009;467:1699-705.

35. Shukla SK, Ward JP, Jacofsky MC, Sporer SM, Paprosky WG, Della Valle CJ. Perioperative testing for persistent sepsis following resection arthroplasty of the hip for periprosthetic infection. J Arthroplast. 2010;25(6 Suppl):87-91.

36. Kusuma SK, Ward J, Jacofsky M, Sporer SM, Della Valle CJ. What is the role of serological testing between stages of two-stage reconstruction of the infected prosthetic knee? Clin Orthop Relat Res. 2011;469:1002-8.

37. Hoell S, Borgers L, Gosheger G, Dieckmann R, Schulz D, Gerss J, et al. Interleukin-6 in two-stage revision arthroplasty: what is the threshold value to exclude persistent infection before re-implanatation. Bone Joint J. 2015;97-B:71-5.

38. Lee YS, Fernando N, Koo K-H, Kim HJ, Vahedi H, Chen AF. What markers best guide the timing of reimplantation in two-stage exchange arthroplasty for PJI? A systematic review and meta-analysis. Clin Orthop Relat Res. 2018:476:1972-83.

39. Chen AF. CORR Insights ${ }^{\circ}$ : Does Change in ESR and CRP Guide the Timing of Two-stage Arthroplasty Reimplantation? Clin Orthop Relat Res. 2019;477: $372-3$.

Ready to submit your research? Choose BMC and benefit from:

- fast, convenient online submission

- thorough peer review by experienced researchers in your field

- rapid publication on acceptance

- support for research data, including large and complex data types

- gold Open Access which fosters wider collaboration and increased citations

- maximum visibility for your research: over $100 \mathrm{M}$ website views per year

At BMC, research is always in progress.

Learn more biomedcentral.com/submissions 